
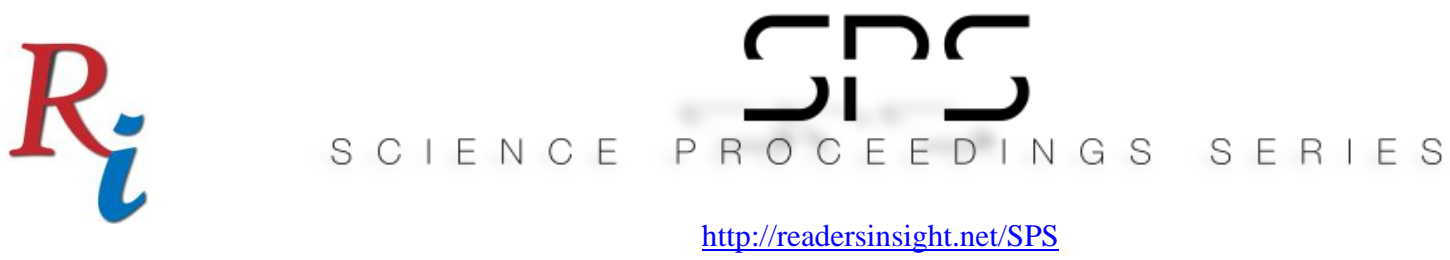

\title{
MOPHORLOGICAL AND THERMAL STUDIES OF ISOLATED SAMMAZ-14 MAIZE COBS NANO FIBRE
}

\author{
Jamila Baba Ali * \\ Department of Polymer and Textile Engineering \\ Ahmadu Bello University, P.M.B 1044 Samaru, Zaria, Kaduna State, Nigeria. \\ jbabaali@abu.edu.ng \\ Abdullahi Danladi \\ Department of Polymer and Textile Engineering \\ Ahmadu Bello University, P.M.B 1044 Samaru, Zaria, Kaduna State, Nigeria. \\ adanladi08@gmail.com

\section{Musa Muhmmad Bukhari} \\ Department of Polymer and Textile Engineering \\ Ahmadu Bello University, P.M.B 1044 Samaru, Zaria, Kaduna State, Nigeria. \\ mmbukhari@gmail.com

\section{Zurina binti Mohamad} \\ School of Chemical and Energy Engineering \\ Universiti Teknologi Malaysia, 81310 Skudai, Johor Baru, Malaysia. \\ r-zurina@utm.my \\ Abubakar Bunza Musa \\ Department of Polymer and Textile Engineering \\ Ahmadu Bello University, P.M.B 1044 Samaru, Zaria, Kaduna State, Nigeria. \\ musabunza@yahoo.com

\section{Jamilu Usman} \\ Department of Chemistry, Faculty of Science, \\ Sokoto State University, Nigeria \\ Jamiluusman2020@gmail.com
}

*Corresponding author's Email: ibabaali@abu.edu.ng

Peer-review under responsibility of 4th Asia International Multidisciplinary Conference 2020 Scientific Committee http://connectingasia.org/scientific-committee/ (C) 2020 Published by Readers Insight Publisher, lat 306 Savoy Residencia, Block 3 F11/1,44000 Islamabad. Pakistan,

editor@ readersinsight.net 

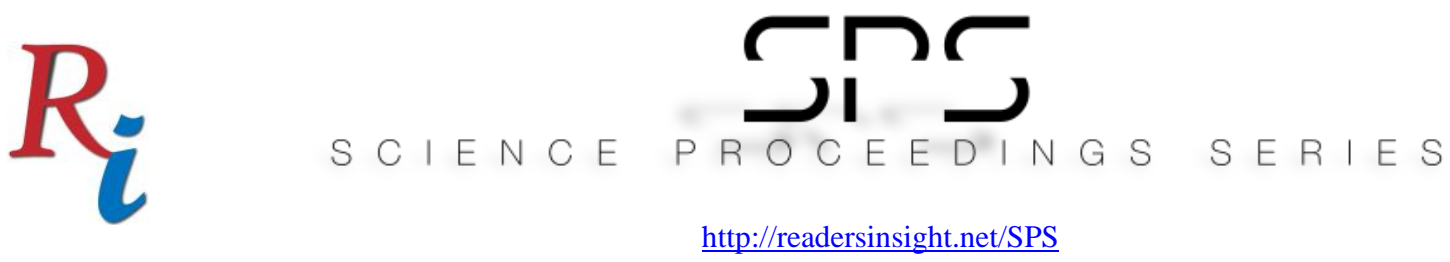

\section{A b s t r a c t}

The growing concerns about global warming and depleting petroleum reserves have made scientists/researchers focus more on the use of natural fibres such as Maize cob, bagasse, coir, sisal among others. About $180 \mathrm{~kg}$ of cobs are obtained from each ton of maize shelled which has little utilization or no utilization. This study utilizes maize cob from SAMMAZ-14 maize variety for the extraction of nano cellulose using Chemico-mechanical method. Alkaline hydrolysis was performed with $5 \% \mathrm{NaOH}$ for $4 \mathrm{hrs}$ with MLR of 1:10. Ball milling was done for $5 \mathrm{hrs}$ with BMR of 30:1. The extracted nanocellulose were characterized by thermal characterization (TG and DTG), field emission scanning electron microscopy (FE-SEM), Energy Disperse X-ray (EDX) and atomic force microscopy (AFM), which confirmed the extracted Maize cob nano fibres (MC-NF) were in nano scale ranging from 1-100 and 1-200nm in diameter and length respectively. Thermal analysis showed MC-NF has more thermal stability than untreated maize cob (MC-UT) whose degradation was initiated at lower temperature with higher charred formation. Morphological studies showed MC-NF has spindle like structures while the untreated maize cob (MC-UT) is plain due to high amorphous portion on the cellulosic structure.

Keywords: Nano Cellulose, Maize Cob Nanofibres, Chemico-Mechanical Treatments, Ball Milling

\section{Rese a r ch H igh I ight s}

1. MC-NF was successfully isolated from sammaz-14 maize cobs via chemico-mechanical method

2. The TGA (TG and DTG) results showed increase thermal stability of the materials in this order MC-NF $>$ MC-UT

3. The non-cellulosic portion (lignin and hemicellulose) were efficiently eliminated by alkaline pre-treatment evidence on the TGA curves.

4. FESEM micrographs showed the alkali-treated MC-NF became more individual and had more sharper and tougher surface compared to the MC-UT 


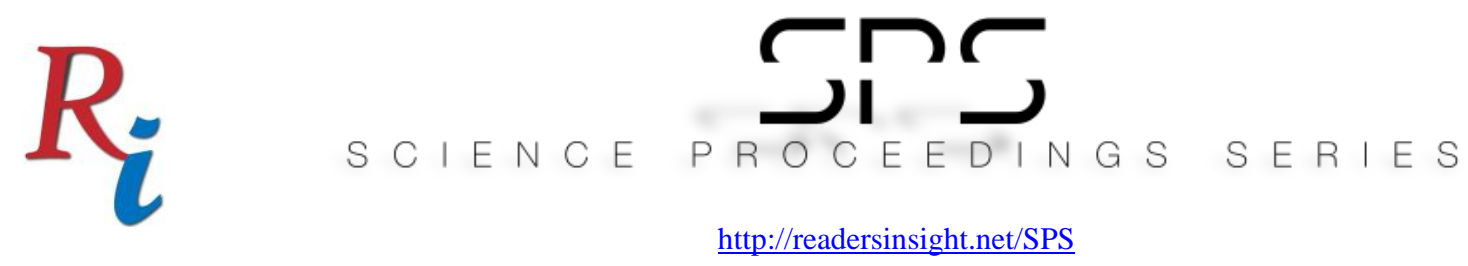

\section{Graphica I A bst ract}
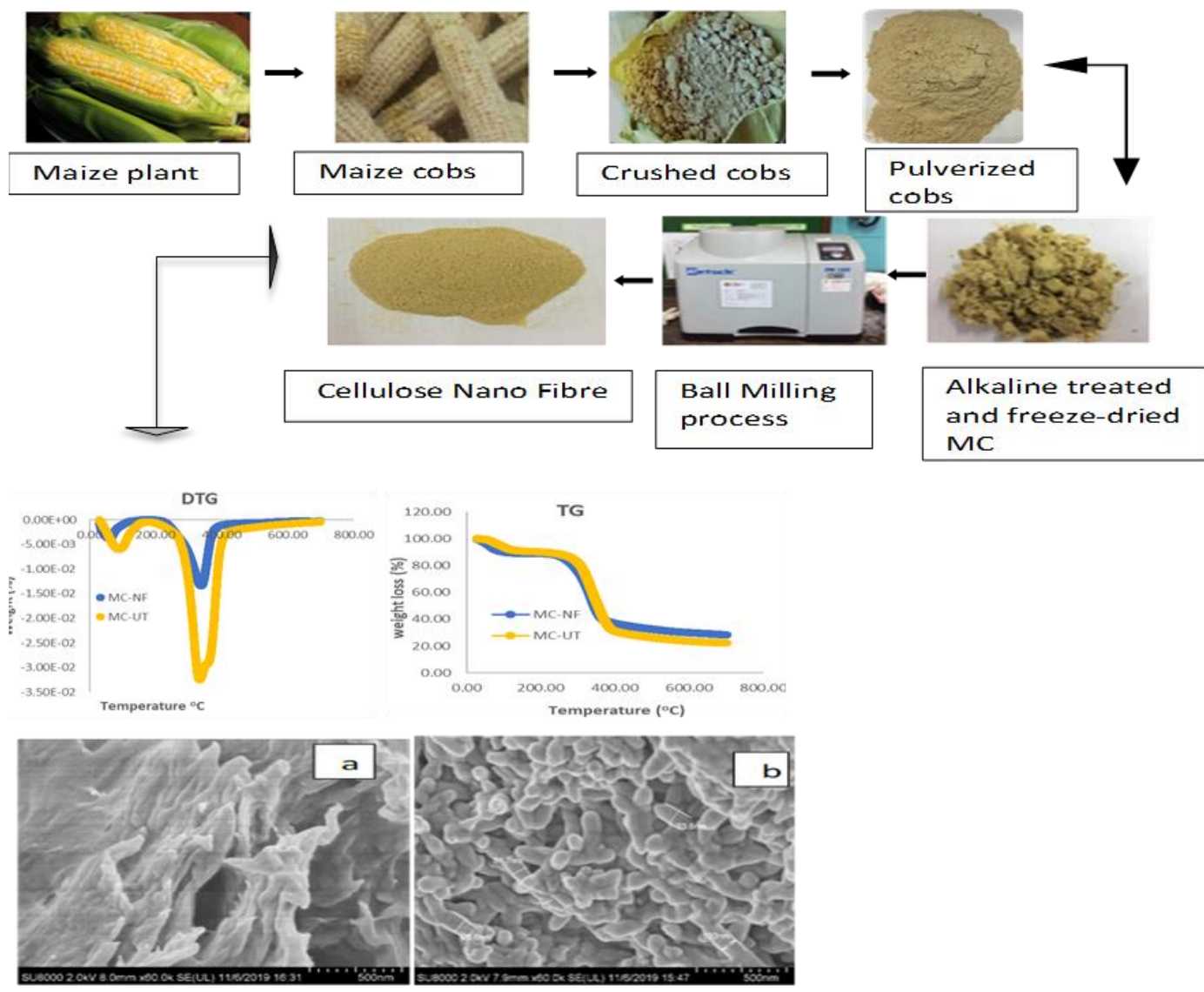

Fig. 1.Graphical illustration of processes involved in the isolation of cellulose Nano Fibre with TG \& DTG curves and micrographs of (a) MC-UT and (b) MC-NF.

\section{Research Objectives}

- The objective of this research is to extract maize cob nano fibre from Sammaz-14 maize cobs and determine its potential use as reinforcement in polymer for bio nanocomposites.

- This resesearch aimed to isolate nano cellulose from sammaz-14 maize cob variety and to characterized it based on it morphology and thermal properties i.e Thermogravimetric Analysis, TG and DTG.

- This work has its significance reflected both in the economic and environmental management of these wastes as maize cob is readily and abundantly available at little or no cost and ball milling is a greener and safer method. 

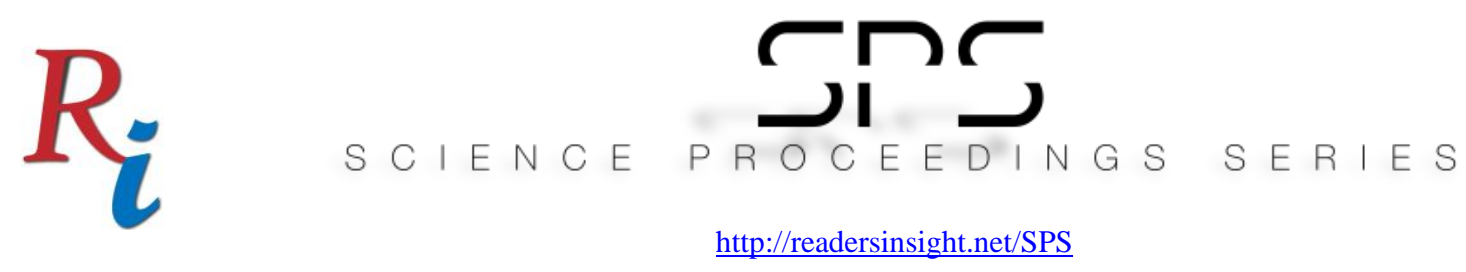

\section{Methodology}

\section{Alkaline Treatment of maize cob powder}

Maize cob (MC) MC-75 $\mu$ m were treated with $5 \% \mathrm{NaOH}$ for $4 \mathrm{hrs}$ at $95{ }^{\circ} \mathrm{C}$ under constant stirring $225 \mathrm{rpm}$ adapted from(1,2). After the hydrolysis, the sample was washed with folds of distilled water until neutral $\mathrm{pH}$ was achieved, the mixture was centrifuged, decanted and freeze dried at $-50{ }^{\circ} \mathrm{C}$ for $48 \mathrm{hrs}$.

\section{Isolation of maize cob nano fibre (MC-NF)}

Planetary ball mill (PM 100) was used for the fibrillation. Alkaline pre-treated cellulose MC was used for the process. The milling was carried out in the dry state, at 450rpm for $5 \mathrm{hrs}$ at room temperature(3), with Ball to Material Ratio of 30:1 using a stainless-steel ball of $10 \mathrm{~mm}$ diameter. Particle size of milled maize cob was analysed after each one hour of milling on laser diffraction principle. using distilled water as the dispersing medium. The dispersion was ultrasonicated for $40 \mathrm{~min}$. The process was repeated until the nanofibres were obtained.

\section{Results}

The isolated maize cob nanocellulose, characterized by thermal (TG and DTG) analysis, the curves showed MC-NF has more thermal stability than untreated maize cob (MC-UT) whose degradation was initiated at a lower temperature which has higher charred residue. The low degradation temperature (onset) observed for MC-UT at $\left(277^{\circ} \mathrm{C}\right)$ as compared to MC-NF (281 ${ }^{\circ} \mathrm{C}$ ) is due to the presence of lignin, hemicelluloses and other non-cellulosic extracts on the MC-UT which decompose at a lower temperature,similar results were obtained by (4). Energy Disperse X-ray (EDX) spectrum shows some negligable percentage of $(0.02 \% \mathrm{Na})$ as impurity on the Nano fibre. Field emission scanning electron microscopy (FE-SEM) and atomic force microscopy (AFM) micrographs showed that the alkali-treated MC became more individual and had more sharper and tougher surface $(5,6)$ compared to the micrograph of untreated maize cob. It also confirmed the extracted Maize cob nano fibres (MC-NF) are in nano scale range.

\section{Findings}

After characterization of the nano fibre, it can be conviently state that, treatment of Maize cob from Sammaz-14 maize varitey, to eliminate hemicellulose, lignin and other cellulosic extracts can be achieve by using $5 \% \mathrm{NaOH}$ for $4 \mathrm{hrs}$ at $95{ }^{\circ} \mathrm{C}$ and extraction or isolation of nano fibre from these cobs can be done by ball milling in the dry state, at 450rpm for $5 \mathrm{hrs}$ at room temperature, with Ball to Material Ratio of 30:1 with a stainless-steel ball of 10mm diameter. 

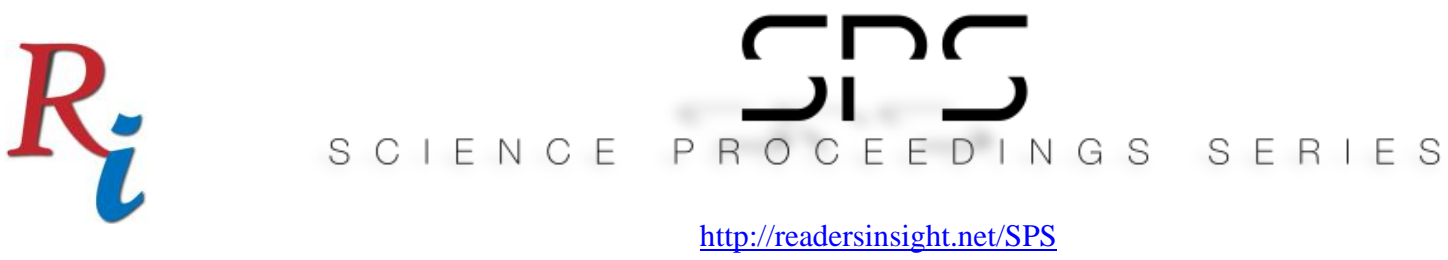

These treatment change the properties of the cellulose to a form that is denser and thermodynamically more stable as observed on the TGA curves.

\section{REFERENCES}

[1] Kumar B, Bhardwaj N, Agrawal K, Chaturvedi V, Verma P. Current perspective on pretreatment technologies using lignocellulosic biomass: An emerging biorefinery concept. Fuel Process Technol. 2020;199.

[2] Theivasanthi T, Anne Christma FL, Toyin AJ, Gopinath SCB, Ravichandran R. Synthesis and characterization of cotton fiber-based nanocellulose. Int J Biol Macromol. 2018;

[3] Phanthong P, Guan G, Ma Y, Hao X, Abudula A. Effect of ball milling on the production of nanocellulose using mild acid hydrolysis method. J Taiwan Inst Chem Eng. 2016 Mar $1 ; 60: 617-22$.

[4] Atiqah MSN, Gopakumar DA, Owolabi FAT. Extraction of Cellulose Nanofibers via Eco-friendly Supercritical Carbon Dioxide Treatment Followed by Mild Acid Hydrolysis and the Fabrication of Cellulose Nanopapers. 2019;

[5] Piras CC, Fernández-Prieto S, De Borggraeve WM. Ball Milling: A Green Technology for the Preparation and Functionalisation of Nanocellulose Derivatives. Nanoscale Adv. 2019;1(3):937-47.

[6] Rohan S, Dassanayake S, Acharya, Sanjit Abidi N. Biopolymer-Based Materials from Polysaccharides: Properties, Processing, Characterization and Sorption Applications. Advanced Sorption Process Applications. IntechOpen; 2019. 